\title{
O Ingresso e Adaptação de Bebês e Crianças Pequenas à Creche: Alguns Aspectos Críticos
}

\author{
Andrea Rapoport ${ }^{12}$ \\ Universidade Federal do Rio Grande do Sul \\ Cesar Augusto Piccinini \\ Universidade Federal do Rio Grande do Sul
}

\begin{abstract}
Resumo
O presente artigo examina algumas questões teóricas e estudos empíricos acerca do ingresso de bebês e crianças pequenas à creche. Analisa-se, em particular, a problemática da separação precoce e as conseqüências para o desenvolvimento infantil do ingresso na creche durante o primeiro ano de vida. Discute-se, ainda, os fatores que interferem na adaptação à creche e as estratégias de enfrentamento utilizadas pelos bebês e crianças pequenas para se adaptar e enfrentar às situações potencialmente estressantes no contexto da creche. Embora haja consenso sobre a complexidade do período de adaptação à creche, existem inconsistências entre os estudos sobre o período mais adequado para ingresso na creche, sendo que algumas idades são apontadas como mais críticas. De qualquer modo, a adaptação à creche depende de diversos fatores, o que não permite fazer previsões com base em um ou outro fator isoladamente.
\end{abstract}

Palavras-chave: Creche; adaptação à creche; comportamento de enfrentamento.

The Entrance and Adjustment of Infants and Toddlers to Daycare Center: Some Critical Aspects

\begin{abstract}
The present article examines some theoretical aspects and empirical studies related to the entry of babies and small children into daycare center. The problems of early separation and its consequences to child development are also examined. Futhermore, it discusses the factors which interfere in adaptation to the daycare center and the infant's coping strategies to deal with potentially stressful events. Although there is consensus about the complexity of the period of adaptation to daycare center, there are some inconsistencies among the studies about the most adequate period for entering daycare center, some ages being pointed out as more critical. In any case, the adaptation to daycare center depends on various factors, which makes it impossible for us to make predictions based on any isolated factor.

Keywords: Daycare center; daycare adjustment; coping behaviors.
\end{abstract}

O contexto social das últimas décadas, em que as mulheres estão entrando cada vez mais no mercado de trabalho tem exigido novas opções para o cuidado alternativo de bebês e crianças pequenas. Quando se fala em cuidados alternativos estes abrangem quatro tipos principais: creches e pré-escolas, famílias de cuidados alternativos onde os cuidados são dispensados a um pequeno grupo de crianças na casa do cuidador, cuidados dispensados por um parente, e cuidados na casa da criança dispensados por um profissional (Davis \& Thornburg,

\footnotetext{
${ }^{1}$ Endereço para correspondência: Rua Pedro Chaves Barcelos, 987/901. Fone: (51) 3304623. E-mail: deiar@terra.com.br

${ }^{2}$ Este artigo é baseado em parte da Dissertação de Mestrado da primeira autora, realizada sob a orientação do segundo autor, apresentada no Programa de Pós-Graduação em Psicologia do Desenvolvimento da UFRGS, Porto Alegre, RS.
}

1994). Embora isto varie entre as culturas, uma das principais opções adotadas no ocidente como cuidado alternativo é a creche.

Inicialmente, as creches no Brasil estiveram vinculadas ao atendimento de populações de baixa renda e o trabalho desenvolvido era de cunho assistencial-custodial, voltado para a alimentação, higiene e segurança física das crianças (Oliveira, Mello, Vitoria \& Rossetti-Ferreira, 1992). Esta realidade foi se modificando, ocorrendo um aumento no número de creches e escolas maternais em todas as classes sociais. Até mesmo mães que não trabalham fora começaram a buscar estes espaços de socialização para as crianças. Segundo Oliveira e colaboradores também mudaram as propostas para o trabalho em creches, que cada vez mais tem adquirido um cunho educativo. Recentemente, a própria Constituição Brasileira de 1988 reconheceu a creche como 
uma instituição educativa, sendo um direito da criança, uma opção da família e um dever do Estado. A partir da nova LDB (20/12/1996) a creche passou a ser incluída como parte da educação infantil responsável pelas crianças até os três anos de idade e as pré-escolas para crianças de quatro a seis anos.

A entrada de bebês na creche, especialmente durante o primeiro ano de vida é um tema que tem gerado controvérsias no meio científico e leigo, pois implica em separações diárias do bebê de sua mãe, enquanto ele ainda é muito pequeno. Embora muitas pesquisas tenham examinado as conseqüências para a criança de seu ingresso na creche, um número mais reduzido tem investigado o processo de adaptação da criança à creche, principalmente em relação à criança menor de dois anos (Fein, 1995; Fein, Gariboldi \& Boni, 1993; Zajdeman \& Minnes, 1991). $\mathrm{O}$ trabalho com crianças pequenas requer cuidados especiais e o planejamento do atendimento é diferente do realizado com as crianças maiores. Deste modo, estudos nesta área são fundamentais, principalmente dentro do novo contexto social em que muitas mães precisam retornar ao trabalho poucos meses após o nascimento do filho.

Neste sentido, espera-se com o presente trabalho contribuir para a compreensão do processo de adaptação de bebês à creche e para capacitação dos profissionais que atuam nesta área. Inicialmente examina-se a problemática sobre separação precoce, e as eventuais conseqüências de cuidados alternativos para o desenvolvimento infantil. A seguir analisam-se diversos fatores que interferem no processo de adaptação à creche. Por fim, discute-se a literatura sobre as estratégias do bebê para enfrentar os eventos potencialmente estressantes durante a adaptação à creche.

\section{A Separação Mãe-Criança como Objeto de Estudo}

Não se podem examinar as questões teóricas sobre separação mãe-criança e suas conseqüências sobre o desenvolvimento infantil sem considerar os estudos realizados por Bowlby $(1958,1968)$ que deram origem à teoria do apego. Uma das suas contribuições são as descrições que fez sobre as reações da criança à ausência materna e a relação destas reações com a sobrevivência das espécies.

Até os anos quarenta, poucos estudos haviam sido realizados envolvendo observações sistemáticas sobre como bebês e crianças pequenas se comportavam quando separadas de suas mães. Um dos primeiros foi realizado durante a Segunda Guerra Mundial por Burlingham e A. Freud (1942 e 1944; citados por Bowlby, 1973/1993) que observaram crianças de zero a quatro anos que estavam separadas de suas mães e eram atendidas em creches. Outro foi realizado por Spitz (1945) sobre crianças internadas por problemas de saúde e que desenvolveram hospitalismo.

Além destes, o estudo solicitado pela Organização Mundial da Saúde a Bowlby em 1951, intitulado Cuidados Maternos e Saúde Mental, teve forte repercussão no meio científico. Neste estudo ele ressaltou as influências negativas, para o desenvolvimento da personalidade, do cuidado materno inadequado na primeira infância e os efeitos de separações neste período (Bowlby, 1995). Bowlby (1976/ 1995) enfatizou que seria essencial para a saúde mental que o bebê e a criança pequena tivessem uma relação calorosa, íntima e contínua com a mãe (ou mãe substituta) e que fosse prazerosa e satisfatória para ambos. Para o autor, uma personalidade estável e auto-confiante se construiria a partir da certeza de contar com o apoio e a presença das figuras de apego e muitas patologias poderiam ser atribuídas à privação do cuidado materno ou descontinuidade na relação da criança com a figura materna durante os primeiros anos de vida. Esta relação com a mãe seria fundamental nos três primeiros anos de vida da criança, mas não devia ser exclusiva, sendo complementada pelos cuidados de outras figuras como pai, irmãos, parentes e outros.

A teoria do apego de Bowlby (1969/1990) postula que a tendência para se estabelecerem fortes relações de apego com determinada pessoa é uma necessidade básica tão importante quanto a alimentação e o sexo. A relação de apego que a criança estabelece com a mãe ou cuidador principal depende da responsividade e sensibilidade desta pessoa com a criança e não da satisfação das necessidades primárias da criança pelo adulto. Além disso, Bowlby assinalou que o longo período da infância humana torna a criança vulnerável e impotente para viver sozinha, principalmente nos primeiros anos de vida. $\mathrm{O}$ apego tem a função de sobrevivência, já que busca promover e manter uma proximidade segura com o cuidador principal. O ser humano está geneticamente programado a responder com medo a determinadas situações potencialmente perigosas, com o intuito de proteção. $\mathrm{O}$ comportamento de apego, envolvendo busca de proximidade pode ser ativado pelo medo, fadiga ou doença. Sendo assim, a ansiedade de separação passou a ser vista como uma disposição humana básica com o objetivo de sobrevivência (Bowlby, 1973/1993).

Bowlby (1968) e Ainsworth, Bell e Stayton (1974) distinguiram entre apego enquanto um sistema comportamental interno que controla a propensão estável para busca de proximidade da figura de apego e os comportamentos de apego, que seriam intermitentes e 
variariam conforme circunstâncias próprias do indivíduo e da situação. O desenvolvimento do apego requer que a criança tenha a capacidade cognitiva de manter sua mãe na memória quando ela não está presente, capacidade esta desenvolvida na segunda metade do primeiro ano (Bowlby, 1989). A visão de um estranho provoca uma resposta de medo em algumas crianças de sete meses e em quase todas de nove meses. Na mesma época em que a criança começa a ter medo de pessoas estranhas passa também a temer objetos e situações estranhas. Ao final do primeiro ano, o bebê aproxima-se do familiar e das coisas agradáveis, afasta-se quando percebe situações potencialmente perigosas e evita o desconhecido e o desagradável. Estas reações são vistas como uma resposta adaptativa fundamental (Bowlby, 1973/1993). Em geral, a angústia durante a ausência materna tem um pico em torno dos dezoito meses e começa a decrescer até que aos três anos de idade a angústia de separação é menos observada (Weinraub \& Lewis, 1977).

As reações da criança à separação materna têm sido distinguidas entre o protesto de separação e a angústia de separação (Bowlby, 1973/1993). O protesto de separação refere-se à resposta de protesto da criança à situação durante a qual a mãe a deixa e a angústia de separação refere-se à resposta da criança por ter sido deixada por sua mãe. Bowlby definiu, ainda, algumas formas de comportamento que são indicativas de medo, despertado pela separação ou por situações, pessoas e lugares estranhos. Exemplos destes comportamentos são o olhar de cautela, inibição da ação, expressão facial assustada, tremor ou choro, busca de abrigo, esconderse e agarrar-se a alguém. Estas formas de comportamento indicativas de medo são seguidas por três tipos de resultados previsíveis: imobilização, distância crescente de um tipo de objeto (ameaçador) e proximidade crescente de outro tipo de objeto (capaz de fornecer proteção).

Existem diferenças nas reações da criança à separação materna prolongada. Enquanto algumas crianças parecem desenvolver-se normalmente após uma experiência de separação e perda, outras apresentam dificuldades para superar estas situações. Segundo Bowlby (1973/1993), isto pode ser explicado por fatores constitucionais, pelas condições nas quais a criança recebe cuidados quando afastada de sua mãe e pela qualidade da relação que mantém com os pais antes e depois da separação. Além disso, os efeitos da separação da criança de sua mãe vão depender da idade da criança, duração da separação e grau da privação. A criança mostra maior perturbação, ao separar-se da mãe, quando ela fica num ambiente estranho ou quando é cuidada por uma pessoa desconhecida, do que quando é deixada com uma pessoa familiar e/ou em um ambiente conhecido. A proximidade da mãe ou da figura de apego diminui o medo a estranhos ou a estímulos novos e facilita a exploração de um ambiente desconhecido.

O trabalho de Bowlby é muito citado por aqueles que se dedicam ao estudo do desenvolvimento infantil, especificamente, na área do apego, separações mãe-bebê e cuidados alternativos. Dentro desta tradição de pesquisa examinam-se, a seguir, estudos atuais que discutem as conseqüências da entrada da criança em cuidados alternativos, principalmente durante o primeiro ano de vida.

\section{Conseqüências da Entrada em Cuidados Alternativos para o Desenvolvimento do Apego}

Embora atualmente não se considere mais o bebê como um ser passivo, mas sim como um organismo capaz e ativo, com um papel importante em seu próprio desenvolvimento, esta nova concepção não trouxe unidade às diversas visões sobre como se dá o impacto do ambiente no desenvolvimento infantil (Gamble \& Zigler, 1986). A partir de diferentes perspectivas teóricas, muitas pesquisas começaram a ser realizadas preocupadas em examinar as conseqüências dos cuidados alternativos, a curto e longo prazo, sobre o desenvolvimento emocional, social e intelectual. Estas pesquisas sobre as conseqüências dos cuidados alternativos para o desenvolvimento da criança têm apresentado resultados inconsistentes (Chase-Lansdale \& Owen, 1987; Goldberg, Greenberger \& Nagel, 1996; McCartney \& Galanopoulos, 1988). Isto pode ser atribuído tanto à diversidade de fatores que podem estar associados às conseqüências dos cuidados alternativos (Bates e cols., 1994; Berk, 1991; Gamble \& Zigler, 1986); como às diferenças nas abordagens metodológicas (Vaughn, Deane \& Waters, 1985); e à dificuldade em se avaliar construtos como o de apego (Clarke-Stewart, 1989; Roggman, Langlois, Hubbs-Tait \& Rieser-Danner, 1994; Thompson, 1991).

Vários estudos têm apontado conseqüências negativas à entrada precoce em cuidados alternativos para o desenvolvimento infantil. Por exemplo, Barglow, Vaughn e Molitor (1987) estudaram bebês de classe média, comparando aqueles cujas mães trabalhavam e que tinham entrado em cuidados alternativos pelo menos quatro meses antes de completar um ano e bebês cuidados pelas mães. A avaliação do apego através da Situação Estranha (Ainsworth, Blehar, Waters \& Wall, 1978) quando os bebês tinham 12-13 meses indicou que uma grande proporção dos bebês, cujas mães trabalhavam fora em tempo integral, foram classificados como de apego inseguro, 
quando comparados com os bebês cujas mães permaneceram em casa durante o primeiro ano de vida.

Com a mesma proposta de avaliar o apego de crianças em cuidados alternativos, Belsky e Rovine (1988) realizaram um estudo longitudinal comparando crianças que entraram antes dos nove meses em cuidados alternativos com aquelas cuidadas exclusivamente pelas mães. Os autores encontram que aos 12 meses crianças com 20 horas ou mais por semana em cuidados alternativos tiveram mais probabilidade de apresentaram apego inseguro. Isto era acentuado no caso de meninos em cuidados alternativos em tempo integral que tinham mais probabilidade de apresentarem apego inseguro do que meninas. Não foram encontradas diferenças entre as crianças que permaneciam em cuidados alternativos por menos de 20 horas e as que permaneciam em casa cuidadas exclusivamente pelas mães. Em outra pesquisa, Belsky e Braungart (1991) também encontraram que crianças com mais de 20 horas semanais de cuidado alternativo no primeiro ano de vida apresentavam mais negatividade, menos independência, choravam mais e se engajavam menos em jogos do que crianças com menos horas em cuidados alternativos.

Considerando que existem fases durante as quais parece ser mais difícil para a criança lidar com separações, Varin, Crugnola, Molina e Ripamonti (1996) estudaram crianças de três anos que haviam entrado no mesmo tipo de creche desde os seis meses. Os resultados mostraram vantagens e desvantagens do ingresso precoce na creche. $\mathrm{Nem}$ todas as crianças que ingressam na creche antes de um ano apresentariam risco de desenvolver problemas emocionais, mas algumas seriam menos hábeis em lidar com o estresse da separação precoce. Os resultados mostraram que crianças que entraram na creche entre 611 meses e 18-23 meses experienciaram mais reuniões difíceis com os pais, em comparação com aquelas que entraram entre 12-17 meses ou depois dos 24 meses. $\mathrm{O}$ grupo de 6-11 meses apresentou também mais dificuldade de tolerar frustração. Os achados endossaram a hipótese de que as separações da mãe ou de outro cuidador estável devido a entrada na creche durante a segunda metade do primeiro ano poderiam introduzir algum distúrbio na construção dos vínculos de apego. $\mathrm{O}$ grupo que ingressou entre 12-17 meses apresentou menos problemas em lidar com a experiência diária da creche, podendo constituir-se num período melhor para ingressar na creche. Por outro lado, crianças que ingressaram na creche mais cedo mostraram níveis mais elevados de brinquedo e comunicação com as educadoras. Isto pode ser devido ao fato de que crianças que entram mais cedo numa creche de boa qualidade têm mais oportunidades e tempo para aprender a brincar com outras crianças.

Alguns autores têm apontado para uma associação negativa entre cuidados alternativos e ajustamento posterior da criança, especialmente no caso de meninos (Chase-Lansdale \& Owen, 1987; Gamble \& Zigler, 1986; Goldberg e cols., 1996). Um estudo realizado por ChaseLansdale e Owen (1987) examinou famílias cujas mães não trabalhavam fora e outras cujas mães trabalhavam fora e retornaram ao trabalho quando o bebê tinha entre duas semanas e seis meses. Os dados revelaram que filhos com menos de seis meses, de mães que trabalhavam fora, apresentavam mais possibilidade de desenvolver apego inseguro do que meninos filhos de mães que não trabalhavam. No caso das meninas, não foram encontrados efeitos negativos. Os autores sugeriram que os meninos cujas mães trabalhavam fora talvez não fossem tratados por seus pais com apropriada responsividade e sensibilidade, porque os pais esperavam mais deles oferecendo-lhes menos apoio do que para as meninas. Estas eram geralmente vistas como mais vulneráveis, e isto era compensado com uma responsividade emocional mais consistente.

Além disso, o estresse da mãe pode afetar a sua disponibilidade emocional e física, trazendo efeitos negativos para a interação mãe-criança e a qualidade do apego (Gamble \& Zigler, 1986). Mulheres que trabalham fora freqüentemente se sentem pressionadas ao lidar com duas jornadas de trabalho. Algumas respondem com menor sensibilidade aos seus bebês porque estão fatigadas, enquanto outras, provavelmente tentam valorizar e encorajar a independência de sua criança o mais cedo possível. Contudo, exigir que as mães permaneçam em casa cuidando do bebê não contribui necessariamente para um apego seguro, especialmente quando a mãe quer trabalhar ou precisa faze-lo em função de suas condições financeiras limitadas (Berk, 1991).

Contrariando em parte os resultados que mostraram aspectos negativos dos cuidados alternativos extensivos, Egland e Hiester (1995) apontaram para a complexidade das possíveis relações que são estabelecidas nesta área. Os autores estudaram as conseqüências a longo prazo da entrada em cuidados alternativos de crianças com menos de um ano, comparando-as com crianças cuidadas pelas mães até os 18 meses. Os resultados mostraram que crianças que apresentavam apego seguro tiveram mais possibilidade de serem negativamente afetadas pelos cuidados alternativos, quando avaliadas aos 42 meses. Por outro lado, para crianças com apego inseguro, ocorreu uma adaptação mais positiva em certas áreas, quando comparadas com aquelas cuidadas na própria casa. Para 
os autores, estes resultados sugerem que os cuidados alternativos precoces podem ter efeitos negativos para crianças que apresentavam apego seguro, enquanto que para crianças com apego inseguro podem ser um fator protetivo, especialmente para sua auto-estima e na área social. Os cuidados alternativos, neste caso, podem compensar uma relação empobrecida com a mãe, através de cuidados mais estáveis e consistentes no ambiente de cuidado substituto.

Outros estudos também não encontraram resultados significativos quanto às conseqüências negativas dos cuidados alternativos iniciados no primeiro ano de vida do bebê. Por exemplo, num extenso estudo americano realizado pelo NICHD (1997) foram investigadas as condições sobre as quais a rotina de cuidados alternativos experienciada pelas crianças nos seus primeiros 15 meses de vida podia levar a um aumento nos índices de apego inseguro. Os resultados não indicaram diferenças na classificação do tipo de apego entre os bebês cuidados pelas mães e aqueles em cuidados alternativos. Nenhum dos fatores relacionados aos cuidados alternativos (qualidade, quantidade, idade de ingresso, estabilidade ou tipo de cuidado) apareceu associado com o tipo de apego do bebê. Houve, entretanto, efeitos significativos relacionados à sensibilidade e responsividade materna. Bebês cujas mães apresentavam baixa sensibilidade e responsividade e que recebiam cuidados alternativos de baixa qualidade ou cuidados não estáveis, eram menos propensos a terem apego seguro.

Dentro desta mesma perspectiva, Thompson (1990) reanalisou os dados de Belsky e Rovine (1988) e de Barglow e colaboradores (1987) e não encontrou diferenças na incidência de apego seguro entre grupos de cuidados alternativos. Embora bebês com cuidados alternativos extensivos nestes dois estudos tenham mostrado uma tendência maior para apego evitativo, esta diferença não foi substancialmente diferente do esperado. Como a maioria dos bebês com experiência de cuidados alternativos precoces apresenta apego seguro em grande parte dos estudos, Thompson acredita que não existe evidência suficiente para justificar a preocupação de que o cuidado alternativo precoce leva a apego inseguro. Roggman e colaboradores (1994) replicaram o estudo realizado por Belsky e Rovine (1988) e também não encontraram relação significativa entre apego e cuidados alternativos.

$\mathrm{Na}$ verdade, quando se fala em cuidados alternativos uma questão fundamental é a qualidade dos cuidados dispensados. Lordelo (1997) apontou para a baixa responsividade dos atendentes em relação aos bebês em muitas creches de má qualidade. Isto ocorreria devido ao grande número de crianças para poucos adultos, além das eventuais trocas de equipe, que podem gerar instabilidade na relação da criança com o adulto, que é submetida a muitas separações e à necessidade de formação de novos vínculos em curto período de tempo. Howes (1990) pesquisou crianças que freqüentavam locais de boa e má qualidade. As crianças que entraram em centros de má qualidade quando bebês tiveram mais dificuldade com pares quando pré-escolares e foram classificadas por suas educadoras do jardim de infância como mais distraídas e menos orientadas para a tarefa. Aquelas crianças que entraram durante o primeiro ano em centros de boa qualidade não tiveram resultados diferentes daquelas que ingressaram maiores.

Com base nestes estudos pode-se dizer que a questão fundamental não parece ser o cuidado alternativo em si, mas a qualidade destes cuidados e suas conseqüências para o desenvolvimento infantil. Tendo em vista a importância de se examinar a qualidade no atendimento alternativo, vários autores (Davis \& Thornburg, 1994; Howes, 1990; Zajdeman \& Minnes, 1991) têm se empenhado em definir critérios para avaliar os locais de cuidados alternativos, como será examinado abaixo.

\section{O Processo de Adaptação à Creche}

Embora muitos autores reconheçam a importância dos primeiros dias na creche e admitam a necessidade de se organizarem atividades especiais neste período inicial, designado como período de adaptação não existe consenso quanto à definição do termo adaptação nem quanto à caracterização deste período. Para alguns autores a adaptação teria início nos contatos iniciais dos pais com a creche, pois as primeiras impressões influenciam a forma como estes vão se relacionar com o novo ambiente (Vitória \& Rossetti-Ferreira, 1993), enquanto para outros, envolveria desde o momento de ingresso da criança na creche até o final do primeiro mês (Bloom-Feshbach, Bloom-Feshbach \& Gaughram, 1980), ou ainda, entre três e seis meses após o ingresso (Fein, 1995; Fein e cols., 1993; Rodriguez, 1981). Em relação ao conceito de adaptação, cada contexto de cuidado alternativo tem suas particularidades, demandas e valores e se as características individuais da criança são compatíveis com estes, então ela tende a ser percebida mais rapidamente como bem adaptada (Klein \& Ballantine, 1988). Por exemplo, as crianças cujo temperamento está de acordo com as demandas culturais e características do grupo de cuidados alternativos tendem a ser julgadas como melhores adaptadas (Klein, 1991). 
Buscando compreender o ingresso à creche, alguns estudos têm mostrado que tanto as mães como as educadoras descrevem as primeiras semanas em cuidados alternativos como altamente estressantes especialmente para bebês e crianças pequenas. $\mathrm{O}$ ambiente desconhecido, as novas rotinas, a alimentação, as pessoas não familiares, as separações diárias e a ausência da mãe colocam-lhes uma significativa exigência social e emocional (Davies \& Brember, 1991). Porém, a adaptação muitas vezes é difícil não só para a criança, mas também para a família e a educadora, pois implica em reorganizações e transformações para todos. A forma como este processo é vivenciado pelas pessoas envolvidas influencia e é influenciada pelas reações da criança (Rossetti-Ferreira, Amorim \& Vitória, 1994). Deste modo, é importante que no período de adaptação a mãe/pai ou outro familiar fiquem junto à criança para auxiliar na exploração deste ambiente estranho e no estabelecimento de novos relacionamentos com as educadoras e outras crianças (Bloom-Feshbach e cols., 1980; Balaban, 1988b). Lamentavelmente isto ainda não é uma prática difundida em todas as creches como demonstra uma pesquisa realizada por Rapoport e Piccinini (2000). O levantamento feito com educadoras de creches da grande Porto Alegre mostrou que apenas um terço das educadoras falaram sobre a importância dos pais ou outro parente permanecer junto à criança no período de adaptação. Em grande parte das creches esta prática facilitadora de uma adaptação com mais sucesso, simplesmente não é adotada.

As pesquisas mostram que as crianças manifestam diferentes reações durante o período de adaptação e estas muitas vezes são utilizadas para classificá-las como bem ou mal adaptadas. Por exemplo, o choro é comum entre crianças durante este período, tanto na chegada quando a criança é deixada na creche pelos pais, como na saída, quando os pais retornam para buscá-la. Mas o choro não é a única reação de perturbação possível por parte da criança. Existem várias outras manifestações como, por exemplo, gritos, mal humor, bater, deitar no chão, passividade, apatia, resistência à alimentação ou ao sono e comportamentos regressivos (Balaban, 1988a; Brazelton, 1994; Vitória \& Rossetti-Ferreira, 1993). A ocorrência de doenças também é freqüente. A criança pode somatizar seus sentimentos em relação à separação apresentando sintomas físicos como febre, vômitos, diarréia, bronquite, alergias, etc. (Rizzo, 1984). Segundo Rizzo, estes sintomas devem alertar os cuidadores para possíveis problemas de adaptação, mesmo que a criança não apresente choro na creche. É possível também que o grande investimento emocional da criança durante a adaptação a torne menos resistente a infecções. Além disso, a criança que se separa com relutância dos pais pela manhã, pode recebê-los no final do dia com pouco entusiasmo (Rodriguez, 1981). Esta criança que parece indiferente no reencontro com os pais freqüentemente provoca sentimentos de preocupação e culpa nos pais, ainda que os dados mostrem que este é um aspecto normal do processo de adaptação.

Dois instrumentos recentes foram desenvolvidos com o objetivo de examinar indicadores de adaptação à creche. Um deles é a escala de adaptação de Varin, Crugnola, Molina e Ripamonti (1996), que se constitui num interessante instrumento que avalia sete conjuntos de indicadores de mal-adaptação da criança no contexto da creche, a saber: 1) pobreza no brinquedo e na comunicação da criança com adultos e pares, com baixa expressão de sentimentos positivos e pequeno interesse nas atividades da creche; 2) sofrimento na separação do objeto de apego, o que também esteve relacionado a uma necessidade geral de estabilidade e baixa tolerância a mudanças; 3) reações agressivas com outras crianças e educadoras, com atividade motora e brinquedo simbólico com conteúdo destrutivo, bem como baixo grau de autocontrole; 4) dificuldade geral durante o reencontro com os pais, envolvendo comportamento evitativo e resistente; 5) baixa tolerância à frustração e ao estresse, baixa resiliência e dificuldade em ser confortado; 6) elevada ansiedade de separação, expressa pelos comportamentos de agarrar-se aos pais durante a separação matinal, chorar e protestar; e, 7) recusa ao grupo da creche, associado a hostilidade com as rotinas da creche, brincando somente com seus próprios brinquedos em padrões estereotipados.

$\mathrm{O}$ segundo instrumento foi desenvolvido por Fein, Gariboldi e Boni (1993) para observar a adaptação de bebês e crianças pequenas à creche. Cada um dos seguintes comportamentos é codificado numa escala de freqüência: 1) interesse em brinquedos e no ambiente; 2) interação com pares; 3) interação com adulto; 4) afeto negativo; e 5) afeto positivo. Tanto o instrumento de Varin e colaboradores (1996), como o de Fein e colaboradores (1993) representam contribuições importantes para se examinar mais sistematicamente o processo de adaptação à creche. Além de poderem ser utilizados em pesquisas, a sua utilização permite que as educadoras tenham informações detalhadas sobre cada criança que inicia na creche.

Durante o processo de adaptação, alguns bebês e crianças pequenas mostram-se quietos e dóceis, sendo muitas vezes negligenciados porque não causam problemas (Balaban, 1988a). Entretanto, a maioria reage de alguma maneira forte a novos ambientes, ainda que 
esta reação nem sempre seja evidente (Bloom-Feshbach e cols., 1980). Brazelton (1994) enfatizou que muitos bebês e crianças pequenas que adaptam-se bem de início podem logo depois começar a dar sinais de regressão em casa. Podem aparecer sintomas que, aparentemente, nada têm a ver com a creche, como problemas de sono e alimentação e acessos de raiva que já pareciam superados.

Deste modo, para avaliar a adaptação de um bebê ou de uma criança à creche, é importante considerar o tempo em que estão na creche. O processo de adaptação não se resume aos primeiros dias, mas pode durar meses. Faltas freqüentes ou irregularidades nos horários de entrada e saída dificultam a adaptação, que tende a se estender por mais tempo (Vitória \& Rossetti-Ferreira, 1993). Além disso, as reações à separação nem sempre desaparecem quando a criança está satisfeita e adaptada à creche. Por exemplo, o período após as férias e as segundas-feiras quando as crianças deixam suas casas após o fim de semana com os pais são eventos que podem estar associados a retrocessos (Balaban, 1988a).

Com o objetivo de examinar a resposta de crianças à separação nos três primeiros meses na creche BloomFeschbach, Bloom-Feschbach e Gaughran (1980) investigaram comportamentos diretamente relacionados com a separação como choro, protesto verbal, ficar grudado nos genitores, bem como comportamentos diretamente relacionados com a educadora. Os autores constataram que as expressões de sofrimento na separação podiam perdurar durante quatro semanas e ainda estar associadas com uma adaptação positiva, sendo o protesto direto uma reação natural e esperada à separação, parte de uma adaptação saudável à creche. A adaptação problemática esteve particularmente associada aos padrões de resposta à separação que envolviam o comportamento apático, retraído e distante da criança.

No estudo realizado por Fein e colaboradores (1993), com crianças de quatro a 19 meses os autores verificaram que assim que o ambiente se tornava familiar, as crianças verbalizavam mais, ficavam mais orientadas para os pares e fisicamente ativas. Alguns sinais de angústia diminuíram durante os primeiros cinco dias de freqüência à creche. Além disso, ao longo de seis meses o interesse e a interação com pares aumentaram, enquanto o afeto negativo e o contato com adulto diminuíram. As análises dos autores indicaram que a adaptação era muitas vezes ainda marginal após três meses, mas substancial após seis. Para os autores, uma das mudanças mais acentuadas durante os primeiros três meses do bebê/criança pequena na creche envolveu os cuidadores, que diminuíram seu contato físico, as manifestações de conforto e a proximidade com os bebês.

\section{Fatores que Interferem na Adaptação do Bebê à Creche}

Existem muitos outros fatores, por vezes pouco estudados, que interferem nas reações e na adaptação de bebês e crianças pequenas aos cuidados alternativos. Entre eles podemos destacar sentimentos dos pais sobre o ingresso do filho na creche, a idade e temperamento da criança e a qualidade do atendimento na creche. $\mathrm{Na}$ maioria das vezes, estes fatores relacionam-se entre si sendo difícil examinar o papel específico de cada um no processo de adaptação aos cuidados alternativos. Para facilitar sua análise eles são apresentados a seguir separadamente.

Um primeiro fator que influencia as reações da criança durante o período de adaptação é a forma como a família, principalmente a mãe, percebe e sente-se com a entrada do filho na creche (Balaban, 1988b; RossettiFerreira \& Amorim, 1996). É comum os pais se sentirem inseguros e desconfiados, principalmente quando se trata do primeiro filho e se for ainda bebê. Existem casos em que é mais difícil para os pais separarem-se da criança do que para a criança adaptar-se ao ambiente da creche (Brazelton, 1994). As mães podem experienciar sentimentos ambivalentes, conscientes ou inconscientes, sobre deixar suas crianças aos cuidados de outras pessoas (McMahon, 1994).

O que motiva os pais a colocarem a criança em cuidados alternativos e a escolha do tipo de cuidado também podem influenciar na adaptação (McKim, Stuart \& OConnor, 1996). Esta decisão vai depender de inúmeros fatores entre eles características individuais da criança, tipo de família (uniparental ou casal), condições demográficas e nível sócio-econômico da família. Segundo os autores, a escolha do tipo de cuidado alternativo esteve muito mais associada a estes fatores do que a problemas na adaptação da criança.

Em estudo realizado por Castoldi (1997), a autora encontrou diferenças qualitativas entre os casos de adaptação fácil e difícil na creche. Por exemplo, crianças com boa adaptação vinham de famílias nucleares, mantinham vínculo de proximidade com a família de origem e seus pais traziam expectativas positivas em relação à elas na escola. Nos casos de adaptação difícil, várias crianças eram de famílias uniparentais, com ausência paterna recebiam pouco apoio de suas mães e as mães não tinham apoio da família de origem. De modo geral, as expectativas das mães eram incompatíveis com as potencialidades dos filhos e existiam vários eventos estressores nas famílias atuais bem como história de perdas significativas. 
Como já foi assinalado acima, uma questão básica na mediação da adaptação é a qualidade do atendimento, para a qual contribui muito a razão adulto-criança existente na creche. No estudo realizado por Howes (1990), centros de atendimento de alta qualidade tinham razão adultocriança de 1:4, para crianças até dois anos e de 1:6 a 1:7, para crianças mais velhas. Nos locais de má qualidade, a razão variava de 1:6 a 1:12, para crianças com menos de um ano e 1:10 a 1:15, para crianças maiores. Além disso, crianças em centros de alta qualidade não tiveram mais do que dois cuidadores diferentes no primeiro ano, um cada turno. A média de cuidadores em centros de má qualidade variava entre três e oito. Outros critérios que se destacam são o tamanho do grupo adequado a cada faixa etária; o espaço físico e o planejamento da rotina; condições satisfatórias de trabalho e a formação dos educadores.

Segundo Zigler e Ennis (1989), a baixa qualidade da creche pode resultar em ansiedade e aumento de estresse nos pais. Por outro lado, quanto maior a satisfação da mãe com o cuidado dispensado, menor a sua apreensão em colocar e manter a criança na creche. $O$ comportamento do cuidador é um dos aspectos da qualidade do atendimento mais relevantes para compreender a adaptação da criança à creche. A qualidade dos cuidados pode depender em parte da habilidade dos profissionais de serem responsivos levando em conta os padrões individuais de cada criança (Fein, 1995). Por exemplo, Hestenes, Kontos e Bryan (1993) verificaram que diferentes aspectos da qualidade da creche estiveram relacionados às expressões emocionais da criança, sendo que o melhor preditor do afeto da criança foi o comportamento da educadora (i.e. cuidados apropriados, envolvimento, engajamento e interação, encorajamento de linguagem receptiva e expressiva, horários apropriados e supervisão das atividades). Crianças com educadoras com maior nível de engajamento expressaram mais afeto positivo enquanto aquelas com educadoras pouco engajadas expressaram mais afeto negativo.

Uma investigação compreensiva da adaptação da criança aos cuidados alternativos requer que sua idade também seja considerada (Zajdeman \& Minnes, 1991). Isto porque algumas etapas do desenvolvimento são mais críticas do que outras para a entrada da criança em cuidados alternativos. Os resultados de um estudo longitudinal realizado por Rodriguez (1981) revelaram que uma adaptação adicional era requerida por bebês e crianças pequenas especialmente, durante dois períodos do desenvolvimento 6-12 meses e 15-22 meses. A primeira faixa etária coincide com a fase de ansiedade frente a estranhos. Nesta fase, a criança adquire a capacidade cognitiva de manter a mãe na memória quando ela não está presente. Do mesmo modo, passa a temer pessoas, objetos e situações estranhas, bem como a separação da mãe (Bowlby, 1973/1993). Segundo Rodriguez, os bebês de 6-12 meses demandavam mais atenção do cuidador, eram freqüentemente relutantes em deixá-lo fora de vista e se tornavam mais competitivos com outras crianças pela sua atenção. Apesar dos esforços, nesta fase, os bebês mostraram-se mais difíceis de serem confortados. A segunda faixa etária examinada pelo autor coincide com a fase descrita por Mahler (1982) como crise de reaproximação. Conforme Mahler, neste momento a criança já caminha e procura afastar-se da mãe, o que de um lado lhe dá prazer, mas de outro acarreta ansiedade de separação, fazendo-a retornar à mãe. Este período de crescente consciência da separação é acompanhado, muitas vezes, de um comportamento da criança de perseguição da sua mãe. A disponibilidade emocional da mãe é fundamental nesta fase. De acordo com Rodriguez (1981) crianças bem adaptadas, que já estavam na creche há meses, durante esta fase, freqüentemente voltavam a protestar na hora da separação, choravam e ficavam grudadas às suas mães como fizeram logo que entraram na creche. Para o autor, estes dados sugerem que o processo de adaptação de bebês e crianças pequenas a cuidados alternativos não é um processo simples e linear, podendo ocorrer retrocessos, associados ao próprio desenvolvimento infantil.

Rodriguez (1981) também observou que nos primeiros dias na creche muitos bebês mostravam comportamento de protesto marcado pelo choro enquanto crianças pequenas ficavam grudadas aos pais. Este protesto ativo era freqüentemente seguido por um período de indiferença com um retorno ao normal dentro dos primeiros dois meses. Estas mudanças podem ser atribuídas à crescente familiaridade com as outras crianças do grupo (Fein, 1995), com os adultos e com as rotinas e ambiente da creche (Howes, 1990). Fein e colaboradores (1993) também encontraram diferenças em aspectos da adaptação de bebês (4 a 11 meses) e crianças pequenas (12 a 19 meses). Por exemplo, crianças pequenas foram mais ativas com pares e mostraram mais interesse/atividade, mas tiveram menos contato com os adultos do que os bebês.

No estudo realizado por Averbuch (1999) também apareceram algumas diferenças na adaptação em função da idade dos bebês que ingressavam na creche (4-5 meses ou 7-8 meses). Foram feitos três estudos de casos de cada faixa etária os quais foram acompanhados durante as dez primeiras semanas na creche. Chamou a atenção a freqüência de adoecimento e conseqüente afastamento 
da creche entre os bebês de 4-5 meses, o que não ocorreu com os bebês de 7-8 meses. Além disso, observaram-se diferenças nas reações na chegada à creche entre os grupos estudados. Enquanto os bebês de 4-5 meses não manifestaram protesto no momento da chegada, dois bebês de 7-8 meses demonstraram, desde o primeiro dia, intenso sofrimento, decorrente da separação da mãe. $O$ choro deles era muito intenso desde o momento da chegada prolongando-se após a partida materna. É possível que a idade destes bebês, na qual é comum uma forte reação frente a estranhos, tenha contribuído para as dificuldades de adaptação.

Outro estudo realizado com educadoras de creche (Rapoport \& Piccinini, 2000) também apontou diferenças na adaptação de bebês em função da idade de ingresso (4-5 meses e 8-9 meses). De acordo com as educadoras, a adaptação dos bebês de 8-9 meses requer maior preparação e cuidado, sendo em alguns aspectos uma etapa mais crítica do que a do outro grupo. Entre os cuidados necessários salientados pelas educadoras destacam-se o horário reduzido nos primeiros dias, a organização do tempo na creche e a preparação da adaptação através de atividades específicas. Além disso, o tempo que o bebê demora a se adaptar parece ser menos previsível para os bebês de 8-9 meses do que para os menores. É possível que isto esteja relacionado com as diferenças individuais mais marcantes neste grupo de bebês maiores. Em relação aos indicadores de adaptação à creche, a interação com a educadora, com o ambiente e com outros bebês foram mais citados para a faixa de 8-9 meses enquanto as manifestações afetivas gerais foram mais mencionadas para os bebês de 4-5 meses.

O temperamento é outro fator que tem sido muito citado nos estudos sobre adaptação da criança à creche (Klein, 1991). Por exemplo, uma criança que inicialmente é tímida e retraída diante de situações novas vai eliciar comportamentos diferentes na educadora do que os provocados por uma que é sociável e acessível a novas situações e pessoas. Além disso, em qualquer grupo pode haver crianças de temperamento difícil que exijam mais atenção. Contudo aquelas que são retraídas e inexpressivas, também necessitam cuidados, porque correm o risco de mais tarde apresentarem dificuldades sociais e emocionais (Fein, 1995). O autor observou que as crianças expressivas recebiam mais atenção quando comparadas com as crianças menos expressivas. Para Fein, algumas crianças, em função do seu temperamento, apresentam maiores dificuldades de adaptação até mesmo em ambientes de cuidados de alta qualidade e com cuidadores sensíveis e responsivos.
No estudo realizado por Zajdeman e Minnes (1991) o temperamento da criança mostrou ter um papel significativo na sua adaptação aos cuidados alternativos. Entre as dimensões de temperamento consideradas, o preditor mais forte, segundo a percepção das educadoras, seria o humor da criança. Quanto mais alegres e felizes as crianças eram percebidas pelas educadoras, mais favoravelmente eram julgadas suas reações ao cuidado alternativo. Por outro lado, quanto mais negativo era o humor da criança, mais adversas as suas respostas à experiência inicial. O segundo preditor foi nível geral de atividade. Quanto mais ativa a criança, mais pobre era sua adaptação. $O$ terceiro preditor significativo foi aproximação e afastamento, isto é, disposição e resistência para experienciar novas situações e encontrar novas pessoas. Quanto maior a disposição para experienciar novas situações e encontrar novas pessoas, melhor a adaptação. Contudo, na avaliação do temperamento da criança feita pela própria mãe, nenhuma das dimensões do temperamento emergiu como preditor significativo para a adaptação. Segundo Zajdeman e Minnes, este resultado pode ter ocorrido porque diferentes contextos e cuidadores (mãe e educadora) podem fazer emergir nos cuidadores diferentes percepções do temperamento da criança. Os autores ressaltaram, ainda, que outros estudos têm mostrado que a criança que mais provavelmente enfrenta algum grau de sofrimento em interações iniciais no ambiente de cuidados substitutos é aquela com estilo de temperamento difícil. Estas crianças mostram adaptabilidade lenta em resposta a mudanças no ambiente, apresentam humor negativo, intensidade de afeto e irregularidade nas funções fisiológicas.

Ao examinarem os melhores preditores de adaptação, Klein e Ballantine (1988) também mostraram que algumas dimensões do temperamento foram mais preditivas de adaptação. A dimensão adaptabilidade foi um bom preditor para adaptação aos pares e adultos, o humor foi significativo para pares e o limiar sensório elevado foi significativo para a adaptação ao programa da creche. Em estudo anterior Klein (1982) já havia mostrado que o nível de atividade elevado por parte da criança era um forte preditor de dificuldade de adaptação em programas orientados para tarefa, mas não em programas abertos e não estruturados, onde existia oportunidade para atividades livres.

Apesar desses resultados, é importante ressaltar que as características do temperamento da criança devem ser consideradas em relação ao ambiente, uma vez que o temperamento sozinho tem valor explicativo limitado (Sanson, Oberklaid, Pedlow \& Prior, 1991). Por exemplo, os autores verificaram que o temperamento como um 
fator isolado foi preditivo em 4\% a $9 \%$ dos casos de problemas de adaptação num estudo com pré-escolares. Os resultados indicaram que fatores de risco isolados presentes na infância não prediziam a adaptação, mas a combinação de dois ou mais fatores de risco esteve associada a problemas de adaptação à creche. Entre estes fatores, temperamento difícil esteve incluído na maioria das combinações que resultou num substancial aumento da preditibilidade. Sendo assim, uma criança, com temperamento difícil, pode não estar em desvantagem num ambiente adequado, com pouco estresse, mas pode ter dificuldades em responder de forma apropriada e adaptativa quando outros estressores estão presentes.

Sem pretender esgotar a análise dos fatores relacionados ao processo de adaptação, dois outros fatores ainda pouco investigados poderiam ser mencionados e que foram examinados por Davies e Brember (1991). Um deles refere-se a diferenças de sexo da criança. Os autores verificaram que a avaliação das educadoras apontava os meninos como mais ansiosos e agressivos e com mais dificuldades de aprendizagem do que as meninas, demorando mais para se adaptar à escola do que meninas da mesma idade. Além disto, eles tendiam a tomar mais o tempo das educadoras. Entretanto, os dados sobre eventuais diferenças sexuais na adaptação não são muito consistentes. Assim, no estudo de Zajdeman e Minnes (1991), os autores não encontraram o sexo da criança nem a interação do sexo com idade como preditores significativos da adaptação da criança aos cuidados alternativos. Outro fator menos investigado seria o turno de freqüência à creche, também estudado por Davies e Brember (1991). Os autores verificaram que as crianças atendidas pela manhã eram, de modo geral, melhor adaptadas do que as atendidas à tarde. Os autores explicaram este resultado pelo fato das educadoras trabalharem nos dois turnos, estando mais cansadas à tarde e serem mais rígidas em seu tratamento e julgamento das crianças deste turno. Além disto, as crianças da tarde não estariam tão dispostas quanto às da manhã, com o conseqüente prejuízo em seu comportamento, dando razão para as educadoras avaliarem como mais difícil a sua adaptação.

Como pode ser constatada na revisão acima, a entrada na creche envolve um conjunto de fatores que influenciam a adaptação do bebê e da criança pequena. Embora estes sejam os mais citados na literatura outros têm despertado pouco interesse dos estudiosos (ex: gravidez e presença de irmão, satisfação da mãe com sua atividade profissional, relacionamento conjugal). $\mathrm{Na}$ verdade, em função da complexidade do processo de adaptação à creche, ainda não se tem um modelo explicativo amplamente aceito que contemple pelo menos os principais fatores e, principalmente, a interação entre eles. Rossetti-Ferreira, Amorim e Silva (2000) apresentam um modelo utilizado para investigar a integração do bebê, de sua família e da educadora durante o processo de adaptação à creche. Este modelo propõe uma rede de significações, de configuração semiótica, para compreender o desenvolvimento humano. Nesta rede aparecem os componentes individuais dos participantes (i.e. mãe, bebê e educadora), os campos interativos que podem ou não ser estabelecidos entre eles, os cenários (i.e. família e creche) e a matriz sócio-histórica (i.e. elementos culturais, econômicos, políticos, ideológicos).

\section{Estratégias para Enfrentar os Eventos Estressantes Durante a Adaptação à Creche}

Cada bebê e criança pequena apresentarão uma reação específica em relação às diversas situações potencialmente estressantes que encontrará durante sua adaptação à creche, utilizando-se de estratégias especificas para enfrentar esta situações. Desde o nascimento os bebês são confrontados com inúmeras situações potencialmente ameaçadoras e desafiadoras que requerem ação e adaptação (Compas, 1987). Todos os bebês precisam adquirir formas de enfrentar o sofrimento e a angústia produzidos pela exposição a estas situações (Carson \& Skarpness, 1988; Compas, 1987; Karraker, Lake \& Parry, 1994). Para os bebês que vão à creche, as separações e despedidas diárias se constituem muitas vezes nas primeiras experiências em que terão de enfrentar o estresse, sendo necessário utilizarem estratégias de enfrentamento para se adaptarem a este novo contexto.

Estratégias de enfrentamento incluem todas as respostas a eventos ou episódios estressantes, que servem para reduzir o estresse (Carson \& Skarpness, 1988; Hock \& Clinger, 1981; Karraker e cols., 1994), aceitá-lo ou tolerá-lo (Carson \& Skarpness, 1988), ou para se adaptar às demandas do ambiente (Compas, 1987). São esforços cognitivos e comportamentais que estão constantemente mudando, para manejar demandas específicas, internas ou externas, que são avaliadas como sobrecarregando ou excedendo os recursos pessoais (Lazarus \& Folkman, 1984).

Considerando que não se pode perguntar a um bebê sobre sua apreciação de um evento, nem sempre fica claro se um evento é estressante (Karraker e cols., 1994). É razoável supor que quando o bebê está demonstrando sinais de angústia deve estar experienciando estresse. Entretanto, alguns eventos podem ser estressantes sem produzir uma emoção claramente negativa, ou o bebê pode enfrentá-lo rapidamente sem que o sofrimento seja 
manifestado. Além disso, uma ocorrência particular pode levar a reações de estresse na maioria dos bebês, mas existem variações na intensidade e tipo de reação dos bebês, resultando em variações nas suas respostas (Karraker \& Lake, 1991). Sinais de angústia podem incluir expressões emocionais negativas (chorar e choramingar, expressões faciais como cólera, tristeza e medo), inibição comportamental, evitação ou retraimento, problemas no sono, na alimentação e adoecimento (Gianino \& Tronick, 1988, citados por Karraker \& Lake, 1991).

No estudo de Karraker e colaboradores (1994), mães de bebês de três a 18 meses foram questionadas sobre as reações de seus bebês a uma larga variedade de eventos cotidianos estressantes. Com base nos resultados os autores elaboraram uma lista de eventos estressantes, muitos dos quais ocorrem no próprio contexto da creche, a saber: 1) eventos físicos (fome, fraldas molhadas e sujas, ser trocado/despido, cair ou bater-se, barulho); 2) eventos interpessoais (terminar uma interação prazerosa, ser deixado sozinho, ser colocado para dormir, ser deixado com uma babá, retorno dos pais depois de uma curta separação, exposição a pessoas não familiares); e, 3) mudanças no ambiente (dormir num novo lugar ou horário, mudança de alimentação, nova rotina de banho). Com base nestes eventos estressantes os autores propuseram duas categorias para classificar estratégias de enfrentamento de bebês e crianças pequenas: estratégias corporais (representam reações físicas e corporais) ou psicológicas. As estratégias psicológicas podem estar focalizadas na emoção (para o bebê tranqüilizar-se) ou no problema (para tentar resolver a situação que causa estresse). Além disto, podem ser realizadas pelo bebê de forma independente ou com auxílio de um adulto, ou ainda serem antecipatórias (manifestam-se antes do evento estressante, quando o bebê percebe que ele está para ocorrer).

As estratégias de enfrentamento durante a infância são afetadas por fatores individuais e ambientais e o grau com que as estratégias vão ser efetivas pode depender da boa adequação entre as demandas da criança e do contexto (Compas, 1987). Por exemplo, a idade e a avaliação cognitiva do bebê são características individuais importantes associadas às estratégias de enfrentamento. Karraker e colaboradores (1994) verificaram que a reatividade dos bebês a eventos estressantes aumentava com a idade. Bebês maiores usaram uma variedade maior de recursos para enfrentar o estresse, refletindo mudanças na maturidade cognitiva e motora e aumento na organização comportamental.

Como já foi salientado acima, a adaptação à creche apresenta para a criança inúmeras situações potencialmente estressantes, com as quais ela vai lidar utilizando-se de estratégias de enfrentamento. Entre estas situações destacase a despedida da mãe/pai, o ambiente novo, o relacionamento com a educadora e outras crianças, as novas rotinas, a necessidade de compartilhar brinquedos, as refeições e o sono.

Em contraste com as separações breves que ocorrem em situações de laboratório, o reencontro com a mãe/ pai depois de muitas horas de separação envolve a reconstrução do vínculo com a mãe/pai transferido para o investimento com o cuidador substituto, pares e atividades da creche (Varin e cols., 1996). Segundo os autores, esta mudança é mais estressante para algumas crianças do que outras, assim como alguns pais são menos sensíveis do que outros às necessidades do filho nesta situação. Algumas vezes, reencontros difíceis ocorrem mesmo depois da criança ter tido uma longa experiência na creche sem problemas. Comportamento evitativo e resistente pode reaparecer algumas vezes durante o reencontro e depois desaparecer novamente.

Field e colaboradores (1984) investigaram as despedidas diárias e os comportamentos de saudação dos dois membros da díade pai/mãe-criança quando a criança era deixada e buscada na creche. Foram observadas crianças entre 3-69 meses atendidas em tempo integral. Os autores verificaram que os comportamentos de despedida e reencontro diferiram em função da idade da criança, sexo, do tempo que a criança estava na creche e sexo do genitor que trazia a criança. Além disso, os estilos de despedida/reencontro destas díades mantiveram certos padrões ao longo do período de observações. Durante o primeiro semestre, crianças pequenas mostraram-se mais angustiadas nas despedidas, mesmo já experienciando despedidas diárias desde a infância precoce. Enquanto os seus comportamentos de sofrimento significativamente diminuíram, nos bebês aumentou o choro ao longo dos dois semestres. Os dados sugerem que estes comportamentos estiveram mais associados à idade do que à quantidade de experiências de despedidas. As respostas diferentes podem estar também parcialmente relacionadas aos comportamentos do genitor. A maioria das meninas foi levada pelas mães à creche e os meninos pelos pais. As crianças levadas pelas mães, diferente das levadas pelos pais, mostraram mais busca de atenção e choro e as mães mais táticas para distrair a criança, demorando mais para deixá-la na creche. Por outro lado, os comportamentos dos pais que envolviam distrair a criança, dar tempo antes de partir e sair escondido estiveram correlacionados com angústia da criança na despedida. Independente de quem deixava 
a criança na creche, aquelas que se mostravam angustiadas na despedida eram ambivalentes nas reuniões.

Outro estudo que se destacou ao investigar as estratégias de enfrentamento das crianças que freqüentam a creche foi desenvolvido por Jonsson, Elwin e Weingarten (1988) com crianças entre um e três anos. Os autores realizaram observações no momento que a criança era deixada na creche por seus pais e na hora em que dormiam na creche. Concluíram que as separações matinais das crianças de seu pai ou mãe constituíam-se num processo complexo e longo. Apesar das crianças estarem freqüentando a creche há pelo menos cinco meses, as reações à separação continuavam fortes em muitos casos. Os autores verificaram, ainda, que o momento da separação compreendia duas fases: a fase em que a criança era deixada na creche e a fase de adaptação, desde a saída do pai/mãe até a criança ter um nível de atuação esperado para sua idade. Durante a primeira fase, muitas crianças não se mostravam inclinadas a deixar a recepção nem tampouco tendiam a se aproximar da equipe ou de outras crianças. Quando chegava o momento dos pais irem embora, as reações de evitação eram prevalentes. Como regra olhavam para seu pai/mãe aparentemente controlando o impacto de tê-las deixado. As reações emocionais imediatas pareciam de negação e após um curto período o impacto emocional da partida era evidente. As crianças podiam ficar caladas, tristes, ansiosas ou ter reações neutras. Nesta primeira fase o pai/mãe e a criança controlavam mutuamente seus comportamentos. O processo de separação teve algumas regularidades para as díades pai/ mãe-criança e traços ritualísticos para cada díade, como por exemplo, a forma com que cada pai/mãe marcava o momento em que ele/ela estava saindo. Durante a adaptação à separação as crianças usavam a equipe da creche como fonte de segurança e contato. Os resultados indicaram também que o fato de ser o pai ou a mãe quem levava tinha efeito nas reações da criança.

Além da chegada e da saída, a alimentação na creche também é uma situação potencialmente estressante, que exige do bebê e criança pequena estratégias de enfrentamento, pelo menos durante o período em que esta situação se constituir em novidade. De uma hora para outra o bebê e a criança precisam se adaptar à alimentação que é oferecida na creche, tanto ao seu cheiro, sabor, consistência, cor, como ao modo como a educadora a alimenta. Um complicador que pode ocorrer é que alguns bebês ao ingressarem na creche passam do leite materno a outro tipo de leite (Amaral, Morelli, Pantoni \& Rossetti-Ferreira, 1996).
Juntos estes estudos apontam para uma nova área de pesquisas que investiguem as estratégias de enfrentamento dos bebês e crianças pequenas que freqüentam a creche. É inegável que a entrada na creche traz em si uma situação potencialmente estressante. Conhecendo-se as estratégias de enfrentamento utilizadas pelos bebês neste contexto se poderá compreender melhor o seu processo de adaptação e planejar intervenções para ajudá-los nas possíveis dificuldades de adaptação.

\section{Considerações Finais}

A revisão da literatura aponta para diversas diferenças nas reações da criança à separação materna, quer esta seja prolongada ou de curta duração. Estudos sugerem que estas reações podem estar associadas com inúmeros fatores, entre eles as diferenças individuais do bebê ou criança pequena (temperamento, idade, sexo) a qualidade da relação que mantém com os pais antes e depois da separação, as condições nas quais a criança recebe cuidados, a duração da separação e grau da privação, e os sentimentos e atitudes dos pais.

Dentro desta perspectiva, muitas pesquisas têm sido realizadas com o objetivo de examinar as conseqüências dos cuidados alternativos, a curto e longo prazo, sobre o desenvolvimento emocional. Estas pesquisas têm apresentado resultados inconsistentes quanto às conseqüências da ida à creche. Algumas apontam maior risco de apego inseguro para bebês que ingressaram em cuidados alternativos durante o primeiro ano de vida por mais de 20 horas semanais, enquanto outras não encontraram esta associação. $\mathrm{Na}$ verdade, independente da idade de ingresso em cuidado alternativo a qualidade do atendimento é fundamental e interage com todos os outros fatores, constituindo-se num importante fator mediador da adaptação. Embora haja consenso sobre a importância da qualidade da creche para a adaptação e desenvolvimento da criança, só recentemente em nosso país com a nova LDB começa a haver uma política nacional de orientação às creches visando adequá-las às necessidades do atendimento mais qualificado. Entretanto, muito precisa ainda ser feito nesta área de atendimento infantil.

Em relação ao processo de adaptação, verifica-se na literatura que embora haja consenso entre os pesquisadores sobre a complexidade do período de adaptação à creche, existem também diversas inconsistências entre os estudos sobre o período mais adequado para se colocar o bebê ou a criança pequena na creche. Alguns estudos apontam como mais críticos o período entre seis e 12 meses, quando se estabelece o apego e aparece a reação frente a estranhos, 
e o período entre 15 e 22 meses, quando, em pleno processo de individuação, a criança caminha para longe da mãe e depois necessita retornar à ela para reabastecerse emocionalmente. Nestes períodos tenderia a ocorrer um pouco mais de dificuldades durante a adaptação e bebês que já se apresentam adaptados podem, inclusive, apresentar retrocessos.

$\mathrm{Na}$ verdade, não existe muito consenso nem mesmo sobre o próprio conceito de adaptação à creche, e menos ainda sobre os fatores que estão mais associados a este processo e como os bebês enfrentam as situações estressantes deste período. A adaptação à creche é um processo gradual em que cada criança precisa de um período de tempo diferente para se adaptar, sendo importante respeitar o ritmo da própria criança e não impor um período pré-determinado para a adaptação. O período de adaptação pode ser mais longo para bebês recebendo cuidados alternativos de má qualidade ou vindo de famílias com problemas. Além disso, faltas freqüentes ou irregularidades nos horários de entrada e saída dificultam a adaptação, que pode se estender por mais tempo. São comuns também regressões no processo de adaptação depois da criança já ter se mostrado adaptada. Dentre as reações manifestadas na adaptação aos cuidados alternativos o choro tende a ser a mais comum entre crianças durante este período, especialmente na chegada quando a criança é deixada pelos pais, como na saída, quando os pais retornam para buscá-la. Mas o choro não é a única reação de perturbação possível por parte da criança. Gritos, mau humor, bater, deitar no chão, passividade, apatia, resistência à alimentação ou ao sono, comportamentos regressivos e a ocorrência de doenças também são indicadores freqüentes de dificuldades na adaptação.

Além da chegada e da saída, vários outros momentos e eventos são particularmente estressantes, como por exemplo a hora de comer, dormir, troca de fraldas ou ida ao banheiro, mudanças de horário e hábitos, mudança de ambiente, ser cuidado por adultos desconhecidos, e brincar com crianças desconhecidas. Para lidar com estes momentos e situações potencialmente estressantes os bebês e crianças pequenas utilizam estratégias de enfrentamento, que podem ser mais ou menos efetivas.

Em função das limitações do bebê e da criança pequena para enfrentar as situações estressantes é importante que se procure reduzi-las ao máximo ou, ao menos, tentar torná-las menos estressantes, além de se buscar formas para ajudar o bebê a enfrentá-las. Propostas simples podem ser introduzidas pela creche, como por exemplo: aumento gradativo no número de horas que o bebê fica na creche ao longo da primeira e segunda semana; a cada dia da semana começar a adaptação de apenas uma ou duas crianças, evitando que todas cheguem no primeiro dia; permitir a presença de um familiar durante a adaptação, no início na própria sala e depois na sala de espera da creche; permitir que o familiar participe das primeiras refeições na creche; manter o número reduzido de bebês e crianças pequenas por cada educadora; evitar ao máximo a troca de educadoras facilitando uma relação estável. Estas práticas auxiliarão o bebê e a criança pequena na familiarização com a nova rotina e permitirão que o familiar adquira confiança e esteja seguro quanto aos cuidados dispensados. Esta segurança do familiar acabará refletida positivamente na adaptação do bebê e da criança pequena que terão mais confiança no ambiente e nas pessoas que os cercam.

Os estudos revisados contribuem para uma maior compreensão sobre o processo de adaptação, mas sugerem que muito ainda precisa ser feito para facilitar adaptação de bebês e crianças pequenas à creche. Novos estudos poderiam contribuir investigando para cada faixa etária quais as rotinas na creche mais adequadas, como organizar o espaço físico, o planejamento pedagógico, como deve ser a formação do educador e como acompanhar a família cujo bebê ou criança pequena ingressa na creche.

\section{Referências}

Ainsworth, M., Blehar M., Waters, E. \& Wall, S. (1978). Patterns of attachment. Hillsdale, NJ: Erlbaum.

Amaral, M. F., Morelli, V., Pantoni, R. V., Rossetti-Ferreira, M. C. (1996). Alimentação de bebês e crianças pequenas em contextos coletivos: mediadores, interações e programações em educação infantil. Revista Brasileira de Desenvolvimento Humano, 6, 19-33.

Averbuch, A. R. (1999). Adaptação de bebês à creche: O ingresso no primeiro on segundo semestre de vida. Dissertação de Mestrado não publicada. Curso de Pós-Graduação em Psicologia do Desenvolvimento, Universidade Federal do Rio Grande do Sul. Porto Alegre, RS.

Balaban, N. (1988a). O início da vida escolar: Da separação à independência. Porto Alegre: Artes Médicas.

Balaban, N. (1988b). Separation: An oportunity for growth. ERIC Reports, (ED 297867). Washington.

Barglow, P., Vaughn, B. E. \& Molitor, N. (1987). Effects of maternal absence due to employment on the quality of infant-mother attachment in a low risk sample. Child Development, 58, 945-954.

Bates, J. E., Marvinney, D., Kelly, T., Dodge, K. A., Bennet, D. S. \& Pettit, G. S. (1994). Child-care history and kindergarten adjustment. Developmental Psychology, 30, 690-700.

Belsky, J. \& Rovine, M. J. (1988). Nonmaternal care in the first year of life and security of infant-parent attachment. Child Development, 59, $157-$ 167.

Belsky, J. \& Braungart, J. M. (1991). Are insecure-avoidant infants with extensive day-care experiences less stressed by and more independent in the Strange Situation? Child Development, 62, 567-571.

Berk, L. E. (1991). Child Development (2a ed.). MA: Allyn and Bacon.

Bloom-Feshbach, S., Bloom-Feshbach, J. \& Gaughran, J. (1980). The child's tie to both parents: Separation paterns and nursery school adjustment. American Journal of Orthopsychiatry, 50, 505-521. 
Bowlby, J. (1958). The nature of the child tie to his mother. International Journal of Psychoanalisis, 39, 350-373.

Bowlby, J. (1990). Apego: A natureza do vínculo (A. Cabral, Trad.). Em J. Bowlby (Org.), Trilogia Apego e Perda (2 $2^{\mathrm{a}}$ ed., Vol.1,). São Paulo: Martins Fontes. (Original publicado em 1969)

Bowlby, J. (1995). Cuidados maternos e saúde mental (V. L. B. Souza \& I. Rizzini, Trads.) ( $2^{\mathrm{a}}$ ed.). São Paulo: Martins Fontes. (Original publicado em 1976)

Bowlby, J. (1989). Uma base segura: Aplicacões c línicas da teoria do apego (S. M. Barros, Trad.) Porto Alegre: Artes Médicas.

Bowlby, J. (1993). Separação (L.H.B, Hegenberg, O. S., Mota \& M. Hegenberg, Trads.). Em J. Bowlby (Org.), Trilogia Apego e Perda (2a ed., Vol.2). São Paulo: Martins Fontes. (Original publicado em 1973)

Brazelton, T. B. (1994). Momentos decisivos do desenvolvimento infantil. (J. L.Camargo, Trad.) São Paulo: Martins Fontes.

Carson, D. K. \& Skarpness, L. R. (1988). Contributors to children's coping: A developmental overview. Wellness Perspectives, 2, 21-25.

Castoldi, L. (1997). As configurações familiares e a bistória de perdas e separações na família: implicações para a adaptação da criança à pré-escola. Dissertação de Mestrado não publicada. Curso de Pós-Graduação em Psicologia do Desenvolvimento, Universidade Federal do Rio Grande do Sul. Porto Alegre, RS,

Chase-Lansdale, P. L. \& Owen, M. T. (1987). Maternal employment in a family context: Efeccts on infant-mother and infant-father attachments. Child Development, 58, 1505-1512.

Clarke-Stewart, K. A. (1989). Infant day care: Maligned or malignant? American Psychologist, 44, 266-273.

Compas, B. (1987). Coping with stress during childhood and adolescence. Psychological Bulletin, 101, 393-403.

Davies, J. \& Brember, I. (1991). The effects of gender and attendande period on children's adjustment to nursery classes. British Educational Research Journal, 17, 73-82.

Davis, N. S. \& Thornburg, K. R. (1994). Child care: A synthesis of research. Early Child Development and Care, 98, 39-45.

Egland, B. \& Hiester, M. (1995). The long-term consequences of infant day-care and mother-infant attachment. Child Development, 66, 474-485.

Fein, G. G., Gariboldi, A. \& Boni, R. (1993). The adjustment of infants and toddlers to group care: The first six months. Early Childhood Research Quarterly, 8, 1-14.

Fein, G. G. (1995). Infants in group care: Patterns of despair and detachment. Early Childhood Research Quarterly, 10, 261-275.

Field, T., Gerwitz, J. L. Cohen, D., Garcia, R. Greenberg, R. \& Collins, K. (1984). Leave-takings and reunions of infants, toddlers, prescholers and their parents. Child Development, 55, 628-635.

Gamble, T.J. \& Zigler, E. (1986). Effects of infant day care: Another look at the evidence. American Journal of Orthopsychiatry, 56, 26-42.

Goldberg, W. A., Greenberger, E. \& Nagel, S. K. (1996). Employment and achievement: Mother's work involvement in relation to children's achievement behaviors and mother's parenting behaviors. Child Development, 67, 1512-1527.

Hestenes, L. L., Kontos, S. \& Bryan, Y. (1993). Children's emocional expression in child care centers varying in quality. Early Childhood Reaearch Quarterly, 8, 295-307.

Hock, E. \& Clinger, J. B. (1981). Infant coping behaviors: Their assessment and their relationship to maternal attributes. The Journal of Genetic Psychology, 138, 231-243.

Howes, C. (1990). Can age of entry into child care and the quality of child care predict adjustment in kindergarten? Developmental Psychology, 26, 292-303.

Jonsson, C. O., Elwin, I. \& Weingarten, B. (1988). The use of attachment objects and transitional equivalents in separation situations: Naturalistic observations in Swedish nurseries. Em P. C. Horton, H. Gerwitz \& K. J. Kreutter (Orgs.), The solace paradigm: An ecletic search for psychological immunity (pp. 229-250). Madison: International Universities Press.
Karraker, K. H. \& Lake, M. A. (1991). Normative stress and coping processes in infancy. Em E. M. Cummings, A. L. Greene \& K. H. Karraker (Orgs.), Life-span developmental psychology: Life-span perspectives on stress and coping (pp. 85-108). Hillsdale: Erlbaum.

Karraker, K. H., Lake, M. A. \& Parry, T. B. (1994). Infant coping with everyday stressful events. Merril-Palmer Quarterly, 40, 171-189.

Klein, H. A. \& Ballantine, J. H. (1988). The relationship of temperament to adjustment in british infant schools. The Journal of Social Psychology, 128, 585-595.

Klein, H. A. (1991). Temperament and childhood group care adjustment: A cross-cultural comparison. Early Childhhod Research Quarterly, 6, 211224.

Lazarus, R. S. \& Folkman, S. (1984). Stress, appraisal and coping. New York: Springer.

Lordelo, E. A. (1997). Efeitos da experiência de creche no desenvolvimento da criança: Uma revisão. Psicologia: Teoria e Pesquisa, 3, 221-229.

Mahler, M. (1982). O processo de separação-individuação. (H. M. Souza, Trad.) Porto Alegre: Artes Médicas.

McCartney, K. \& Galanopoulos, A. (1988). Child care and attachment: A new frontier the second time around. American Journal of Orthopsychiatry, 58, 16-24.

McKim, M., Stuart, B. \& O'Connor, D. L. (1996). Infant care: Evaluation of precare diferences hypotheses. Early Education and Development, 7, 107119 .

McMahon, L. (1994). Responding to defences against anxiety in day care for young children. Early Child Development and Care, 97, 175-184.

NICHD Early Child Care Network (1997). The effects of infant child care on infant-mother attachment security: Results of the NICHD study of early child care. Child Development, 68, 860-879.

Oliveira, Z. M., Mello, A. M., Vitória, T. \& Rossetti-Ferreira, M. C. (1992). Creches: Crianças, faz de conta \& cia. Petrópolis: Vozes.

Rapoport, A. \& Piccinini, C. A. (2000). Concepções de educadoras sobre a adaptação de bebês à creche. Manuscrito submetido para publicação. Instituto de Psicologia, UFRGS.

Rizzo, G. (1984). Creche: Organização, montagem e funcionamento. Rio de Janeiro: Francisco Alves.

Rodriguez, D. T. (1981). Infant day care: How very young children adapt. Children Today, 10-12.

Roggman, L. A., Langlois, J. H., Hubbs-Tait, L. \& Rieser-Danner, L. A. (1994). Infant day-care, and the "file drawer problem". Child Development, 65, 1429-1443.

Rossetti-Ferreira, M. C., Amorim, K. S. \& Vitória, T. (1994). A creche enquanto contexto possível de desenvolvimento da criança pequena. Revista Brasileira de Crescimento e Desenvolvimento Humano, 4, 35-40.

Rossetti-Ferreira, M.C. \& Amorim, K. (1996). Relaçẽes afetivas na família e na creche durante o processo de inserção de bebês. Trabalho apresentado no IV Simpósio Latino-Americano de Atenção à Criança de 0 a 6 anos, Brasília.

Rossetti-Ferreira, M.C., Amorim, K. \& Silva, A. P. S. (2000). Uma perspectiva teórico-metodológica para análise do desenvolvimento humano e do processo de investigação. Psicologia: Reflexão e Crítica, 13, 281-293.

Sanson, A., Oberklaid, F., Pedlow, R. \& Prior, M. (1991). Risk indicators: Assesment of infancy predictors of pre-eschool behavioural maladjustment. Journal of Child Psychology and Psychiatry, 32, 609-626.

Spitz, R. A. (1945). Hospitalism, an inquiry into the genesis of psychiatry conditions in early childhood. Psychoanalitic Study of the Child, 1, 63-74.

Thompson, R. A. (1990). The effects of infant day care through the prism of attachment theory: A critical appraisal. Em N. Fox \& G. G. Fein (Orgs.), Infant day care: The current debate (pp. 41-50). Norwood, NJ: Ablex.

Thompson, R. A. (1991). Infant day care: Concerns, controversies, choices. Em J. V. Lerner \& N. L. Galambos (Orgs.), Employed mothers and their cbildren (pp. 9-36). New York: Garland.

Vaughn, B. E., Deane, K. E. \& Waters, E. (1985). The impact of out of home care on child mother attachment quality: Another look at some enduring questions. Monographs of Society for Research in Child Development, 50 (serial 209), 110-135. 
Varin, D., Crugnola, C. R., Molina, P. \& Ripamonti, C. (1996). Sentisitive periods in the development of attachment and the age of entry into day care. European Journal of Psychology of Education, 11, 215-229.

Vitória, T. \& Rossetti-Ferreira, M. C. (1993). Processos de adaptação na creche. Cadernos de Pesquisa, 86, 55-64.

Zajdeman, H. S. \& Minnes, P. M. (1991). Predictors of children's adjustment to day care. Early Child Development and Care, 74, 11-28.

Weinraub, M. \& Lewis, M. (1977). The determinant of children's responses to separation. Monographs of Society for Research in Child Development, 172, 42(4).
Zigler, E. \& Ennis, P. (1989). The child care crisis in America. Canadian Psychology, 30, 116-125.

Sobre os autores:

Andrea Rapoport é psicóloga, doutoranda do curso de pós-graduação em Psicologia do Desenvolvimento da UFRGS.

Cesar Augusto Piccinini é psicólogo, doutor em Psicologia (Inglaterra), pesquisador do CNPq e professor do Instituto de Psicologia da UFRGS. 